\title{
De un quehacer histórico y casual a un saber que la historia tiende a hacer difuso
}

\author{
Teresa Durán $P^{*}$ y Nelly Ramos $P^{* *}$
}

\begin{abstract}
In this article we present the necessity to transform the relation that is established between anthropologists and indigenous people into an analysis and reflection for the purpose of producing knowledge in the realm of anthropology, particulary in Chile and the Araucania Region. We postulate this context of analisys as a response, on the one hand, to the evolution of anthropology and the ethics of anthropological study. On the other hand, it responds to the expanding participation and globalization of the participants of the indigenous movement worldwide. The antithesis of this posture is found in anthropological works that break the relationship postulated from an individualized and apparently individualistic practice related to eventual paradigm changes presented on the first world and experimentally replicated in our context.
\end{abstract}

\section{Resumen}

En este articulo planteamos la necesidad de transformar en materia de análisis y reflexión la relación que, a propósito de la producción de conocimiento de corte antropológico, se establece entre antropólogos e indígenas en contextos regionales y/ o nacionales, particularmente en el país y en la región de La Araucanía. Los autores postulan este ámbito de análisis como respuesta, por un lado, a la evolución de la antropología y a la ética de los antropólogos, y por otro, a la participación cada vez más amplia y globalizada de los representantes del movimiento indígena del mundo. La antítesis de esta postura radicaría en obras de antropólogos que rompen esta relación postulada a través de una práctica individualizada $e$ individualizadora, al parecer a tono con eventuales cambios paradigmáticos propuestos en el primer mundo y replicados experimentalmente en nuestro medio.

\section{Introducción}

$\sqrt{1}$ ste artículo reflexiona en torno a la relación que la antropología establece con el "objeto", en los términos actuales, el sujeto histórico con el que construye conocimiento y establece relación desde un particular enfoque disciplinario. La revisión aborda cuatro décadas y concierne, en lo particular, a los acercamientos a la sociedad mapuche.

Gran parte de las temáticas de los antropólogos, particularmente en el Tercer Mundo, conciernen a sujetos que cada vez, se han ido haciendo más visibles, tanto por los movimientos que ellos mismos protagonizan, como el interés que suscitan en los medios de masas e incluso, entre los propios antropólogos. Nos referimos a los pueblos indígenas. Nos damos cuenta de que estos pueblos - sea en forma directa y/o indirecta -, reciben los vaivenes de los esquemas epistemológicos de la antropología, en realidad, de las ciencias sociales y reaccionan a ello. Como sabemos, estos pueblos son motivo, mayormente, de a) políticas públicas, con sentido integracionista y/o alienatorio; b) interpretaciones de sentido común por parte de diversos sectores sociales (medios de comunicación, organismos privados, nacionales e internacionales); y c) interpretaciones por parte de los llamados especialistas, dentro de los cuales los antropólogos quizás sean los más recurrentes.

Quienes hemos sido formados en antropología, sabemos que este quehacer es cambiante y que presenta matices diferentes según sea el centro internacional del cual provenga: Europa, Estados Unidos, últimamente, México. La influencia formadora es ineludible, aunque conlicve necesariamente flcxibilidad adaptativa a los contextos y a las particularidades personales. Normativamente, se acepta que todo conocimiento, en términos de afirmaciones no casuísticas, se sustente en reiteradas pruebas empíricas, las que a su vez, deben construirse sobre la base de un acercamiento teórico, metodológico y básicamente cpistemológico explícito. En la medida en que este principio se asume, sentencias como "la objetividad no existe", "la antropo-

\footnotetext{
- Teresa Durán P. es antropóloga, Directara del Centro de Estudios Socioculturales y de la Escuela de Antropología de la Universidad Católica de Temuco.

* Nelly Ramos P. es antropóloga, sociolingōista, docente e investigadora dol Departamento de Languas de la Facultad de Artes y Humanidades de Ia Universidad Católica de Temuco.
} 
logía a través de la etnografía no es científica" no tienen mucho. sentido, porque tal principio apunta a establecer una base de trabajo, no un pedestal de verdad absoluta. Así, la delimitación de una temática, la estructuración y diferenciación entre una perspectiva cognoscitiva social y/o voluntaria o intencionada, que responda a tal acercamiento de un modo coherente, constituye la base relativa y operacional del quehacer. Nos parece que los textos de antropología que se encuentran dispersos por el mundo responden a csa estructura clemental, aunque la disciplina se nutre de modo cspecial de las críticas que los cultores hacen de las obras que aparecen a través del tiempo. En otras palabras, los comentarios de los trabajos tanto como los trabajos mismos constituyen la cara pública y privada del quehacer que se denomina antropológico, en el marco de una estructura cpistemológica relativamente estable: definir qué se desea hacer, cómo sc hará y por qué.

¿Qué sentido tiene estc alcance introductorio? Crear un contexto empírico - analítico respecto del cual resulte coherente el contenido general del texto que, con ocasión de reconocer un quehacer disciplinario, hemos considerado pertinente abordar.

En efecto, en la situación contemporánea y más allá de los conflictos intelectuales que se estén dando en las disciplinas de las ciencias sociales, no nos parece pertinente condicionar a una relación privada aqucllo que pueda cstablecerse entre el conocimiento disciplinario, vale decir, antropológico, y el pueblo indígena, dada la amplitud de las interrelaciones sociales $y$, además, la participación que los propios representantes de estos pueblos tienen, tanto en el conocimiento social que se difunde sobre y/o en relación a ellos, como respecto del llamado conocimiento especializado o disciplinario.

¿Qué ocurre con cada nueva obra o texto que aparece en la escena pública? Para algunos especialistas, su impacto se evaluará respecto de la crítica del círculo en el cual el autor se mueve y respecto de un orden social coherente con ese círculo. Para otros, en cambio, entre los cuales nos situamos, la obra debe ser evaluada respecto de su impacto en todos los órdenes categoriales anteriormente mencionados. Según este prisma, deben registrarse, al menos, algunas formas de impacto de la obra en referencia en, por un lado, el quehacer antropológico localmente situado $y$, por otro, la vida social, considerando que se nutre de los aportes de distintos actores, particularmente los propios mapuche. En el caso particular que nos preocupa, creemos quc esta delimitación es la que corresponde, dado que ciertas obras están señaladas por los rasgos típicos de las que suponen un impacto: estar editadas por una editorial de prestigio, haber sido presentadas y relevadas en importantes medios de comunicación, etc. Aunque nos atrevemos a suponer que muchas veces este andamiaje proviene del impacto que circunda al autor, siempre será relevante comentar la forma y el contenido del texto. Es este material el que se relacionará, por una parte, con la coetaneidad antropológica y su precedente y, por otra, con los sectores de la vida social. Por razones de espacio, esta scgunda argumentación será más bien đe carácter ilusirativo. A continuación revisaremos algunas obras de carácter antropológico que comprometen a la población mapuche hasta fines de los '90.

\section{Tendencias teóricas y de conocimiento sobre la sociedad y cultura mapuche}

Cuando la antropología disciplinaria llegó a Chile, lo hizo a través de obras que se centraban en temáticas y géneros aparentemente unívocos. Era la época de los '60. Estas obras se divulgaron mayormente en contextos universitarios y/o museos, con escaso impacto social conocido. Nos referiremos a los textos siguientes:

- Estructura social mapuche, de Luis Faron,

- Antïpaiñamko. Moral y ritual mapuche, de Luis Faron,

- Trasfondo cultural sobre la crianza de los hijos, de Ines Hilger, ${ }^{1}$

- Huenün Ñamku: Un indio araucano de los Andes, de Ines Hilger.

Estos cuatro textos representan, al menos, dos tendencias teóricas de tradición antropológica reconocida, provenientes de la cscuela norteamericana: la estructural funcionalista y la culturalista. Al menos en el ámbito académico, estos constituyen textos de consulta, a los que regularmente conviene recurrir. Más allá de las limitaciones derivadas de los acercamientos teóricos, estos textos incluyen información valiosa acerca de sistemas culturales específicos. En el caso de Faron, sobre los sistemas de parentesco, económico, sociopolítico, el mundo supernatural, particularmentc el moral y ritual a través del concepto de congregación ritual. Capítulos especiales se le otorgan al chamanismo y la brujería, en el marco de la hermandad y la estructura de solidaridad, en los términos del autor. Hilger, por su parte, desglosa su texto sobre los Araucanos de Chile en 21 acápites y abarca el ciclo vital, desde los factores prenatales hasta el ambiente material del hogar.

Mientras los primeros textos desencadcnaron desde los '70 una polémica disciplinaria en torno a la posición sociopolítica y sociocultural de la sociedad mapuche respecto de la sociedad nacional, los segundos aportan de modo sistemático antecedentes acerca de un estilo de vida desde la perspectiva ética, que también es discutible, proporcionando, no obstante, importante información acerca de la normativa mapuche de crianza de la época. Nos parece particularmente útil para este comentario centrar la atención en el cuarto texto ya citado del segundo autor, Huenün Ñarnku, En las palabras de Mcad, en el prólogo del texto, se trata de una etnología de rescate que intenta capturar un viejo estilo que, con posterioridad, sólo será posible recrear; este rescate es posible en la medida en que algunos miembros de estos pueblos tienen la voluntad de informar y la capacidad de hacerlo en forma auténtica y rigurosa. Lo intercsante para nosotros es que Hilger no denota el texto como una biografia,

1 L.a referencia del texto original está en lengua inglesa bajo el titulo Aravcanian child life and its cultural background, Smithsonlan Institute, U.S.A., 1957. 
ni tampoco como estudio propiamente etnográfico. La característica habría sido el trabajo voluntario de Huenün Ñamku, "porque él deseaba que se supiera la verdad sobre su pueblo...". Hilger, por su parte, consideró que él ejemplificaba los iđeales araucanos: era inteligentc, de incuestionable integridad, orgulloso, autónomo, cortés y afectuoso. El texto comienza por presentar a Huenün Namku como pescador y trampero; luego explicita el método de transcribir las notas de campo. A continuación aborda los temas de construcción de la ruka y la preparación de los alimentos, las tradiciones, las canciones, los conocimientos y prácticas curativas. Luego recoge la versión de Huenün Ñamku sobre la brujería y la magia, las creencias religiosas y los ceremoniales. Concluye el texto presentando la vida de Huenün N amku con su esposa y su hijo y el matrimonio al estilo araucano. En otras palabras, es un texto avanzado a la teoría de su época en el sentido de que intenta abrir espacios en el género metodológico legitimado, transitando desde la descripción normativa a la perspectiva de los individuos.

En cuanto a la polémica disciplinaria, esta comenzó a hacerse más explícita dos décadas más tarde cuando surge el texto antropológico y etnográfico posestructuralista de Milan Stuchlik (1976) quien aborda el tema de la estructura social para el caso mapuche, involucrando a los antropólogos precedentes. Es interesante consignar que Faron parte reconociendo que "los mapuche constituyen una de las más grandes sociedades en funcionamiento de Sud América y son muy diferentes cultural y socialmente a los chilenos...". Esta es una observación que se puede verificar y respecto de la cual los mapuche no podrían contraponerse. En efecto, a nivel internacional estos son textos de consulta obligada para miles de estudiosos del mundo interesados en esta sociedad. Uno de los problemas serios que introduce el texto, sin embargo, se refiere a la interpretación estructural - funcionalista del autor respecto a que el sistema de reducciones impuesto por el Estado chileno "tiene menos importancia que la estructura de valores mapuche que ha permanecido intacta...". En efecto, el autor plantea que las instituciones sociales mapuche han estado "relativamente equilibradas desde el gran cambio a la vida en reducciones..." (ibid., 189). Aún más, sostiene que, precisamente a raíz de este sistema de reducciones, los mapuche han cohesionado su sistema de vida... cuestión que ha sido materia de controversia no sólo en el plano disciplinario, sino entre los propios mapuche. Efectivamente, Stuchlik demostró los profundos cambios que el sistema reduccional produjo en la sociedad y cultura mapuche, tanto en el sistema de parentesco como en el sociopolítico. Desde el marco teórico en el que se sitúa, incorpora un concepto operacional de "comunidad", que entiende, por un lado, como sector geográfico respecto del cual los mapuche sitúan su residencia y, por otro, como una zona vital respecto de la cual re-crean sus relaciones de parentesco, ceremoniales, sociales y económicas. En otras palabras, demuestra que si bien el sistema de reducciones representó un modelo administrativo impuesto que redujo drásticamente el territorio, los mapuche como individuos y con capacidad de negociar entre ellos su propio estilo de vida, se rearticulan frente a esas nuevas condiciones protagonizando procesos de cambio en todas las esferas de su vida social (Stuchlik [1976], 1996; Vidal, 1999).
Pero quizás el aporte más significativo de esa antropología para este comentario fue haber demostrado que el conocimiento social, en un marco de relaciones interétnicas desequilibradas e injustas, no representa necesariamente un conocimiento "objetivo" o demostrable, en el sentido de que se sustenta a sí mismo, sino que simplemente relativo a los antecedentes que maneja quien formula ese conocimiento. Así, es imposible incorporar "objetividad" a los estereotipos que la sociedad chilena ha elaborado sobre lo mapuche por cuanto, por un lado, estas afirmaciones son cambiantes según las épocas y el estilo de relaciones que la propia sociedad chilena va proponiendo a la mapuche $y$, por otro, por los propios comportamientos del pueblo mapuche, configurados no sólo respecto de estas condicionantes externas, sino también respecto del conocimiento derivado de su propia historia.

Dos principios de distinto orden, pero interrrelacionados entre sí, son destacables en este argumento: en primer lugar, por primera vez en Chile, se incorpora al quehacer disciplinario un marco teórico - epistemológico que permite liberar al conocimiento científico social de la seudo - objetividad derivada de las teorías interpretativas pre-científicas, al incorporar de modo pionero la participación plena de los propios sujetos en su historia - sean mapuche o chilenos. En segundo lugar, dada la interrelación histórica que ambos tipos de sujetos han sostenido desde más de un siglo, se plantea la necesidad de que todo conocimiento social se relativice respecto de quien lo formula y de sus bases históricas normativas y situacionales, dado que, en este ámbito, tal conocimiento tenderá a ser estereotipado y antojadizo respecto de los fines particulares de cada actor. La postulación de un principio epistemológico de tal orden concierne a la naturaleza misma del objeto de las ciencias sociales así como a su aplicación al campo de las relaciones socioculturales que viven los mapuche en la época contemporánea (y que pueden aplicarse de igual modo en cualquier otro ámbito). Ello generó un tipo de antropología en la región - década de los '80 y '90 - caracterizable, al menos, por los siguientes rasgos:

- Esfuerzos descriptivos respecto de contextos delimitados, la mayoría de ellos de carácter interétnico.

- Construcción de referentes interpretativos respecto de áreas socioculturales interrelacionadas y de referentes societales específicos y globales.

En definitiva, se trata de una antropología que postula la vigencia de una relación interétnica asimétrica e intenta demostrar el impacto de esta relación - asumida o no por los actores - en diversos campo: del desarrollo, de la educación, de la legisłación. Este tipo de antropología, ha sido reproducida mayormente respecto de temáticas sociales en otros centros del país.

Sin abandonar la postura posestructuralista, la época de los ' 90 representa el momento de visibilizar el mundo indígena no sólo como actor social, es decir, como constructor de relaciones, sino como autor que participa en la escena cognoscitiva y de los significados. Es decir, se asume que debe avanzarse mucho más en el proceso de capturar los procesos interactivo - interpretativos de los actores, particularmente de aquellos que enfrentan pro- 
cesos sociales más que como representantes de un estilo particular de interpretar el mundo. Se trabaja con sectores que detectan marcos normativos relativamente ideales respecto de sistemas culturales específicos y también con otros que han aceptado negociar - conscicntemente o no - su estilo de vida con el sociocultural global (Durán T. y Quidel J., 1994, Durán T. y Catriquir D., 1992; 1996; Durán T., Catriquir D. y Llanquinao G., 1997; Durán T. y Quidel J.; 1998; Vidal A., 1998, 1999).

Los aportes sustantivos de este tipo de antropología podrian enumerarse como siguc:

a) Delimitan responsabilidades respecto de problemas "objetivos" tales como la pobreza de la sociedad mapuche, según los parámetros oficiales, $y$ el retraso de la sociedad nacional en asumir su condición pluriétnica en el marco de los derechos indígenas internacionales.

b) Intentan comprender el campo interactivo social, cultural y cognoscitivo amplio entre la sociedad mapuche y sus distintos y variados sectores y la sociedad nacional, estableciendo parámetros de conocimiento relativo entre ambas, depenđiente de factores situacionales específicos.

Cabe destacar, por ejemplo, uno de los aportes antropológicos más sustantivos de la última década y considerada en el presente una obra de consulta obligada; nos referimos a Medicinas y Culturas en la Araucania (Citarella L. et. al. 1995). Esta obra se compone de cinco partes, destinada la primera a los sistemas socioculturales y medicinales en la IX Región; la segunda, a la medicina mapuche; la tercera a la medicina popular; la cuarta, a la medicina occidental y, la quinta, a la articulación entre medicinas.

El aporte antropológico de esta obra consiste, a nuestro juicio, en situar cl contexto gencral que permite el reconocimiento de los distintos sistemas médicos, su diferenciación y sus eventuales o posibles interrelaciones.

Estos aportes, no obstante, dada la diferenciación entre conocimientos especializados considerados oficiales o de jerarquía social y otros marginales, han provocado impactos menores y específicos, sin divulgación en los medios de comunicación.

Mientras, tanto la sociedad mapuche como la nacional a través de sus respectivas diásporas de sectores y actores, compiten por una mayor validez de sus respectivos conocimientos, constituyéndose los antropólogos, justificadamente o no, en los chivos expiatorios de esta contienda.

\section{Confrontación entre el conocimiento antropológico y las perspectivas indigenistas y/o reivindicacionistas}

Las primeras manifestaciones reivindicativas de los sectores mapuche en la arena sociopolítica nacional provienen de los líderes de organizaciones sociales -constituidas estas como parte de los movimientos socialcs mapuche generados como reacción al sistema reduccional; así lo muestran los antropólogos metropolitanos R. Foerster y S. Montecino (1993).

La característica de estas manifestaciones de las primeras décadas del siglo es que se dirigen mayormente a la sociedad chilena, en su conjunto, contra las políticas específicas del Estado: educacionales, agrarias, económicas, una vez que talcs políticas y las tendencias políticas contingentes, las han involucrado. Esta última actitud sería recogida en los ' 90 bajo el título: $\mathrm{Del}$ involucramiento a la reflexión. Políticas Educacionales hacia la Sociedad Mapuche, por Catriquir y Durán (1996). Hacia el interior, las organizaciones oscilarían entre incorporar contenidos religiosos y cosmovisionales propios o enfatizar modos diversos de integración a la sociedad nacional. No se vislumbraban a comienzos de los ' 80 consideraciones relativamente profundas acerca de la cultura o la condición social gencral de vida del pueblo por parte de sus representantes. Las únicas obras conocidas en esa época provinieron, primero, de Manuel Manquilef (1974) y Martín Alonqueo (1979), ambas de corte descriptivo e influidas notoriamente por esquemas cognoscitivos externos. Avanzando el siglo hacia los ' 90 , se tomaría conocimiento de una reacción relativamente más profunda respecto de la manipulación de que se siente objeto la religión mapuche respecto de la católica y de la protestante a través de la presentación y posterior publicación del trabajo: El mundo mapuche de Armando Merino Lefío, desde su posición de longko lafkence. "Los antecedentes, conceptos y los diversos contenidos que involucra el tema son expresiones auténticas vertidas por nuestras autoridades tradicionales: longko, ngenpin, machi, dungunmachife y otros"-se adelanta... "En estas líneas está 10 que por tiempo inmemorial se ha mantenido en secreto y que nos permite hoy reconstruir el mundo mapuche...". El autor recomienda "no emitir juicio ni concepto desde lo occidental...". El texto va desde la articulación del mundo mapuchc, avanza con el mundo mapuche en el kultrun y concluye con la conceptualización de las tres dimensiones. Este texto será discutido más tarde por un machi lafkence (1999), particularmente respecto de las tres dimensiones del universo mapuche, planteando que es una interpretación todavía influida por la religión católica; discrepa también respecto de otros conceptos particulares en el marco de la cosmovisión mapuche. Es decir, el sector mapuche comienza a bacerse presente con su conocimicnto para confrontar a quienes por mucho tiempo han hablado por ellos: primeramente los misioneros y luego los antropólogos, y en general, los especialistas de las ciencias sociales y de la educación. Mientras tanto, en esta década tiene lugar también la aparición del sector intelectual mapuche universitario, en algunos casos, a través de especialistas de la historia o de la misma antropología. Una de las instancias más sobresalientes ocurre en el 93, a propósito del Seminario ¿Qué entiende la Ley Indígena por Pueblo Mapuche?, organizado por la Universidad Católica y varias instituciones privadas. En esta oportunidad, Pedro Marimán llama la atención sobre la categoría de etnia, concepto que en el plano de las ciencias sociales planteó el tema de las relaciones interêtnicas $\mathrm{c}$ intraétnicas, particularmentc en el con- 
cepto europeo. Este intelectual mapuche se apropia del concepto desde una perspectiva ideológica -connotación que él atribuye a todos los conceptos usados por los científicos sociales, algunos de los cuales considera abiertamente peyorativos y limitantes para el movimiento indígena, tales como clan o tribu. El carácter étnico, entendido como diferenciación social basada en criterios de poder y de territorio, le parece útil, "en tanto cada etnia es una nación en potencia...". Reconoce, al mismo tiempo, que las posibilidades de establecer relaciones interétnicas en un plano de igualdad se posponen indefinidamente, en tanto la nación chilena no asuma tal carácter aunque se lo asigne a tres agrupaciones indígenas: la mapuche, la aymara y la rapa nui. Pero, conceptualizaciones como etnia e indígena habían sido fuertemente rechazadas por el movimiento indigenista mapuche, aymara y rapa nui a fines de 10 ' 80 y comienzo de los ' 90 , a raíz de las propuestas de ley emanadas desde los sectores oficiales concertacionistas. Se expresó una fuerte resistencia a tales términos usados en la antropología, como ocurriera anteriormente con los conceptos de "araucano" y "minoría étnica". En efecto, sabemos que los primeros antropólogos los usaron profusamente hasta la primera mitad del siglo. Dado este rechazo o simplemente porque los especialistas tomaron en cuenta el carácter relativo de todo concepto y el impacto que estos producían en el sujeto vivo al que se referían, ellos dejaron de usarse y han sido reemplazados, en la mayoría de los casos por "sociedad y/o cultura mapuche", o simplemente por "pueblo mapuche". El concepto impugnado es usado hoy, mayormente, por sectores no especializados. Una situación similar se conocería más tarde, aun cuando con resultados menos unívocos, cuando el sector especializado metropolitano protagonizó una discusión pública en torno a si la sociedad nacional sostiene relaciones fronterizas o de intercambio amplio (no étnico) o relaciones interétnicas, tomando en cuenta los antecedentes históricos y de análisis (Foerster R. y Vergara I., 1996). En este caso, son dos sectores no mapuche los que discuten en relación al modo como cada uno interpreta la participación mapuche en las relaciones sociales en el país, tema que, por un lado, no ha sido asumido plenamente por los representantes estatales $y$, por otro, tampoco por los intelectuales nacionales, en sus amplias implicancias.

Por otra parte, una confrontación directa y formativa había tenido lugar a comienzos de la década actual en el Seminario denominado Cambio y Resistencia de la Sociedad y Cultura Mapuche entre especialistas y representantes del movimiento indígena e indigenista de la época. En esa oportunidad los sectores mapuche mostraron haber incorporado la perspectiva evolucionista de orientación antropológica y se resistían al rescate del conocimiento mapuche "antiguo", asumiendo su obsolescencia..., se mostraban, por otra parte, desinformados acerca de los procesos globales concernientes a los pueblos indígenas en el contexto de América Latina y del propio pueblo mapuche, respecto de las políticas estatales. Era la época en que se oponía un alfabeto "con carácter étnico", propuesto por un miembro mapuche de ese sector, a otro llamadio por ellos "de los especialistas", aunque dentro del grupo en que este se validara se encontraran varios mapuche. Esta actitud de rechazo al conocimiento técnico por el sector de la resistencia mapuche se mantendría hasta el presente. Son representantes de este sector quienes impugnaron durante este año la aparición de un Diccionario Ilustrado Mapuche, Castellano, Inglés, adquirido y distribuido por el Ministerio de Educación; las razones serían dos: usurpación del conocimiento mapuche y uso masivo y oficial del alfabeto previamente impugnado.

Entre los especialistas no mapuche también tendrían lugar sendas discusiones indirectas, con participación de representantes del pueblo mapuche, en una u otra dirección. La primera se refiere al concepto particular de desarrollo acuñado por el movimiento indigenista pro-ley indígena. Nos referimos al concepto de "desarrollo con identidad". Esta fue una propuesta conceptual que justificó tal movimiento y, al mismo tiempo, ofreció una salida a la controversia cultura - desarrollo, propia de la época. En efecto, se re - valida la postura desarrollista, tradicionalmente adoptada por la sociedad chilena, y le atribuye el carácter de identitaria, sea en una perspectiva simbólica o activa. Esta propuesta será impugnada más tarde en base a la experiencia y se explicita su imposibilidad cuando la controversia no es advertida por los sectores indígenas o simplemente cuando, para estos, el fenómeno identitario es prioritario (Durán T, 1995).

En el contexto mapuche propiamente tal otra controversia digna de destacar se genera a raíz de los resultados del último censo (1992). Mientras el movimiento mapuche urbano considera que los datos confirman la importancia de este sector y que el cambio profundo de la sociedad mapuche es significativo incluso para definir las próximas propuestas de desarrollo, el sector mapuche rural, particularmente activo respecto de la reproducción de los patrones culturales identitarios, se opone al liderazgo de aquel sector. Para ello propone la reinstauración de aquellos principios que habrían marcado históricamente la resistencia mapuche a la sociedad nacional, más aun, este sector re - instala el concepto "mapunche" para diferenciar, desde una perspectiva étnico - cultural, los estilos mapuche menos o más auténticos respeto del proceso aspirado de autonomía y, por ende, de relaciones interétnicas con la sociedad nacional (Pérez, P., Bacic, R., y Durán, T., 1998; Quidel, J., 1999; Durán, T, y Quidel, J., 1998).

Así las cosas, las interacciones entre sectores mapuche y entre estos y los no mapuche (especialistas y/u oficialistas), han caracterizado el escenario nacional y, particularmente, el regional a través de los medios de comunicación, redes científico sociales, eventos públicos y/o privados. En los últimos tiempos y con el resurgimiento del movimiento indígena no oficial, se registran interesantes posturas, situadas en diferentes posiciones teóricas. Por un lado, el movimiento indígena aludido se nutre de conceptos y planteamientos derivados del derecho indígena 
internacional, al mismo tiempo que asume la posibilidad de la autogestion mapuche revalidando el conocimiento propio sin negar la posibilidad de articulación con el mundo indigcnista oficial y el propio gobierno (Hucnchuñir, 1999). Por otra parte, los actuales representantes del gobierno concertacionista atribuyen estas modalidades "a un sector minoritario no representativo", y permanecen fieles al concepto de pueblo indígena centrado en las comunidades definidas por ley... Se nutren del concepto de desarrollo con identidad, proveniente del sector espccializado oficial y adjudican criterios étnico - culturales que no son reproducidos de modo fácil por la gente mapuche, como el de propiedad colectiva y la interculturalidad. Esta postura es mayormente reproducida por sectores mapuche liderados por movimientos igualmente concertacionistas y negada de modo diferente por cada uno de los matices adoptados por el movimiento no oficial. En este escenario se configuran redes de leallades variadas y controvertidas.

\section{Conflictos intelectuales de las últimas décadas}

En el nivel intelectual amplio, la relación entre globalización y cultura ha concentrado gran parte de las discusiones y controversias. En la periferia latinoamericana, la forma en que estos fenómenos se articulan es ambivalente y susceptible de variadas interpretaciones en las palabras de Hopenhayn (1997), quien identifica cinco miradas, cada una con una base de posibilidades: la ilustrada y crítica que registra más integración al mismo tiempo que más desintegración; la apocalíptica, que se caracteriza por la aparición de imágenes "cada una para cada consumidor de imágenes"; la tribalista, propia de la proliferación de tribus urbanas; la culturalista, que descansa en último térnino en las sintesis interculturales como posibilidad de vivir y convivir con la globalización; y, la posmoderna, que enfatiza la disipación de fronteras y que hace más aleatorio, disperso y de corto plazo el mundo cotidiano.

¿Cómo han sido conceptualizados estos cambio en las ciencias socialcs y particularmente en la antropología?

En el plano general, nos parece pertinente citar aquí a Gellner (1994), catedrático de Antropología Social en Cambridge, que atribuye el germen de disolución de las bases epistemológicas de Occidente a las características socioculturales de EEUU, considerado intelectualmente etnocéntrico por el pensamiento europeo. El hecho de que los significados no sean idénticos se ha vivido en Europa más que cn América, en donde se percibe como revelación. En otras palabras, rechaza cl nihilismo implícito en cl relativismo planteado por antropólogos americanos; no así cl relativismo mismo, tendencia epistemológica que, a su juicio, continúa siendo válida, siempre que no excluya la moralidad y se sustraiga a la tendencia de considerar el conocimiento como el fin o verdad última. En otras palabras, aboga por un conocimicnto amoral y transcultural, como punto de partida de cualquicr antropología o pensamiento social, y por superar la tesis simple del relativismo. El relativismo simplificado, en la perspectiva de Gellner, no puede asumirse por cuanto en materias antropológicas se trabaja con relaciones asimétricas y no relativistas. En otras palabras, Gellner discute la propuesta del relativismo hermenéutico a la que se ve llevada la antropología, porque no tiene un correlato de realidad; la imagen de una eventual simetria la concibe como "una parodia total y desastrosa del mundo en que vivimos" (ibid., p.76).

El planteamicnto de fondo de Geliner respecto de la tendencia al nihilismo cognitivo de los antropólogos de hoy, es que estos han reducido la vida social a "sistemas de significado", dejando de lado el cómo operan las estructuras sociales quc, en su concepción, establecen la asimetría de facto...

En este sentido, la hermenéutica sería el nombre moderno del idealismo (ibid., p. 84). Por otra parte, la crítica del autor a la antropología posmodema apunta al hecho de que, en la actualidad, deja de Jado cuestiones de por sí interesantes, como una gramática gencrativa de los signifícados. En otras palabras, sosticne que "no se pueden investigar los significados idiosincráticos sin ubicarlos en el contexto de la naturaleza tal como lo ve nuestra cultura científica y, en particular, en el contexto de las impresionantes desigualdades de poder de los diversos estilos cognitivos" (ibid., p.89, las cursivas son nuestras).

El nihilismo cognitivo posmoderno "niega y oscurece las tremendas diferencias cruciales para la comprensión del desarrollo actual de la sociedad humana" (ibid., p.89). Su postura afirma que: "hay un conocimicnto externo, objetivo, trascultural: un conocinicnto más allá de la cultura..." (ibid., p.96). La condición transcultural de este conocimiento es que no tiene obligaciones para con ninguna cultura y propende a un procedimiento único basado en principios tales como:

- Todos los hechos y observadores son iguales

- No hay fuentes o afirmaciones privilegiadas

- Todos los hechos y aspectos son separabies; las totalidades son desmembrables mediante el pensamiento.

Estas discusiones se vuelven comprensibles si las relacionamos con el pensamiento de las sociedades desde donde emergen. Al haberse preocupado (los norteamericanos) de decodificar mediante la observación y codificar mediante la escritura, obligaron a la antropología a redefinir su estilo. El conocimiento de la retórica en la que la etnografía se sustenta y articula, la transforma, quizás, en una nueva opción de las hurnanidades. Esta es la tendencia a creer que la antropología no puede persistir al margen del discurso literario. Desde ella, se niega la posibilidad de "la objetividad cienúfica", ya que no se basa sino en una subjetividad más... En su forma más profesional, el análisis dc la antropología como obra literaria ha sido propuesto por Geertz (1989), uno de sus exponentes más famosos que nos induce a pensar que "la calidad de una monografía etnográfica no depende tanto de la amplitud de las descripciones y de la abun- 
dancia de datos, como de la habilidad del etnógrafo para convencernos de la evidencia de lo contado" (Díaz, V.L., 1986:15). El prologuista de la obra de Clifford y Marcus (1991) va más lejos y plantea que "la contradicción entre lo biográfico y lo científico, sólo puede superarse satisfactoriamente si el etnógrafo asume su calidad de autor" (ibid., p.15). Esta afirmación, recurrente hoy en la academia, se sostiene con esa otra de que en el mundo integrado al hoy, todos estamos conectados... y más aún, en la perspectiva de otro exponente, Tyler, conocemos o pretendemos hacerlo, a través de discursos, siempre condicionados por la propia cultura del etnógrafo. Este tipo de autores se defiende contra el nihilismo que se les imputa alegando que su relatividad no es arbitrariedad. Para el prologuista antes citađo, precisamente, "analizar un texto es descubrir algunas de las claves fundamentaies de su proceso creativo" (ibid., p. 17). Estas claves se encontrarán en el ante-texto, en el mundo que vive el autor, en su cosmovisión y sistema de valores o en el contexto histórico o en los aspectos más particulares de su biografía. En suma, la producción de autores como Geertz, Pratt, Crapanzano, Rosaldo, Clifford, Tyler, Hard y el mismo Marcus, conformaría un estilo de etnografía, que Díaz califica de "poética perceptiva - e interpretativa..." y que se encaminaría a "una comunicación intima entre autor y lector..." "que no se constituye en un instrumento para cambiar la realidad, sino para entenderla mejor...". En la voz de Clifford, los análisis posmodernos que introduce "toman como motivo las prácticas del pasado y las del presente, al margen de futuras y posibles sistematizaciones... se amalgaman las fronteras de lo artístico y de lo científico" y se precisan las variantes del quehacer etnográfico actual. Destaca entre otros, el subgénero de la autorreflexión elaborada a partir de las notas de trabajo de campo (ibid., p.43), por ejemplo, y varios otros "[...] como un rechazo de los modos de investigación al uso...", hacia una clarificación del análisis hasta ahora cerrado a la escritura, que es a lo que principalmente propende el etnógrafo. Para ello cuestiona el epíteto de "realista" como materia susceptible de experimentación práctica tanto como lo es de especulación teórica. Finalmente, plantea que la etnografía no sólo será literatura.

Mientras tanto, en México, durante la década actual, antropólogos como García-Canclini (1992) aportan, según la mirada posmoderna, un nuevo estilo antropológico de conocer, particularmente las formas de multiculturalidad.

Precisamente, el estudio de las megaciudades obliga a considerar los cambios económicos, tecnológicos y simbólicos, cuyo entrelazamiento revela indiscutiblemente diversas dimensiones de los procesos sociales. Ve el horizonte disciplinario en estudios que interralacionan lo micro y lo macrosocial y lo cualitativo y lo cuantitativo en una teorización integral. En esta perspectiva, los estudios etnográficos se estiman riesgosos ya que, por una parte, las descripciones monográficas no logran explicar la situación y por otra, el populismo político puede usarlas para sus fines. Así, García-Canclini aboga por ir a una redefinición global del objetivo del quehacer antropológico, en el marco tradicional de la preocupación por lo otro y los otros... en la que lo otro y los otros están en el propio antropólogo. Finalmente, el autor compromete a la disciplina en "la toma de decisiones en los dilemas del carnbio de siglo".

Nos interesa incorporar, en este panorama teórico de fines de los '90, la obra Sueño con Menguante, ${ }^{2}$ particularmente por ser la última y más conocida. Al igual que en los casos anteriores, intentaremos situarla en forma y contenido, en el trasfondo en el que se desenvuelven las relaciones entre el movimiento indígena y sus matices, las interpretaciones de los antropólogos mayormente regionales-, las políticas gubernamentales, y respecto del marco teórico-filosófico que sustenta toda obra intelectual. Para hacerlo necesitamos caracterizarla con mayor detalle.

Es un texto que se compone de dos partes: la primera titulada "Sueño con Menguante", conformada por ocho capítulos, que alcanza a 211 páginas; la segunda, obedece al título "Cuaderno de Terreno", con cinco apartados que cubren 38 páginas.

Una característica sobresaliente de este texto deriva de ser denotativo del género biográfico acerca de un actor relevante de la sociedad mapuche: la machi, como persona. Esta obra sería entonces una Biografía de una Machi..., según se identifica en la tapa posterior del libro. En esta referencia se designa al machi como un curandero de oficio y al texto como "un libro de sabiduría, un texto que narra el viaje de una huinca escogida y guiada por una machi por los caminos de la sapiencia mapuche...".

El primer capítulo presenta el primer encuentro entre la autora y la persona a la que ésta biografía: la machi de Prado Huichahue, en 1972. La intermediación habría provenido de la mujer mapuche que la había criado en Santiago. La mayor parte del capítulo se dedica al viaje y a las autorreflexiones de la autora, algunas de explícito corte etnográfico literario posmodemo, otras de estricto orden personal, tales como: "cuando Florencia me invitó a Temuco ese verano, intuí que ese viaje marcaría mi existencia. La ansiedad y el desasociego embargaron mis días y sólo deseaba estar allá para escuchar y ver lo que ella me había relatado tantas veces: brillos malignos, cueros vivos en el agua, animales que con sólo mirar paralizan, monstruos mitad gallina y mitad culebra, cabezas aladas...".

El capítulo segundo relata un viaje más a Prado Huichahue, en donde ocurre un nuevo encuentro entre la autora y la machi, en un nguillatun de Roble Huacho; su esposo era el hermano de la amiga que la había introducido en el sector, su sector.

En este capítulo la machi se relaciona con ella, introduciéndola en el ceremonial, más aún, enseñándole a bailar "para que orara bailando, para que rogara sagradamente...". La autora dice luego en primera persona: "No podía negarme a esa transfiguración, a ese cambio de ropajes para ser otra sin serlo mayormente, no podía rehusar esa nueva pero vieja identidad que C.R. me 
ofrecía". En este capítulo se intercalan expresiones etnográficas de la machi, con descripciones y autorreflexiones... En este viaje la autora da cuenta de cómo la machi le ordena imperativamente "todo lo que te diga tienes que grabártelo en la mente...", aceptando clla el compromiso.

Así, el capítulo tercero se destina a presentar los primeros relatos que podrian considerarsc biográficos, ya que consideran tiempos desde el nacimiento y de la niñez, incluyendo cl poder de curar y también la propia enfermedad de machi que la acompaña por varios años.

El capítulo cuarto incluye el relato del viaje de la autora para responder a la primera invitación expresa de la machi a su casa... su sueño con C.R. en cl tren... Intercala referencias casuísticas sobre el viaje y autorrefcrencias tales como "fingí no saber que su pupila solitaria se apodera de mí como una diferencia, aparento estar concentrada y atenta al carnino...". En este capítulo aparecen también notas de la época, sobre la Reforma Agraria, el encuentro con la machi en su casa y la constancia de que ella también la había soñado... "¿ Sería posible que nuestros sueños se cruzaran?", se pregunta... En esta convivencia, ya la machi comienza a hablaric de las plantas. Ella ha aprendido de Ngenechen... -dice-, recibiendo lo que C.R. le dice. Le enseñan a no privarlas... "porque todas tienen un püllü...". Conoce el espacio donde C.R. fabricaba sus remedios. "El mundo en ese cuarto era el pasado y el presente para mí...". En esta permanencia larga se le revelan claves de los sueños, "del canto del chucao a la izquierda.... del gato lavândose las manos... supo de dos muertos, de aquéllos que habían organizado el asentamiento... compartió el velorio...". Aquí, como en todos los capítulos, incluye autorreflexiones del tipo: "Su casa a la que me había invitado y que conocí cl día de su velorio". Al regreso, relata su primer encuentro con dos alemanes... y luego, de su camino hacia entender las rclaciones sociales entre las personas con las que traba amistad...

El capítulo quinto es el más propiamente biográfico, ya que incluye el relato que C.R. le había hecho sobre su vida con la abuela, cómo decide enviarla a Santiago, su vida allí, el primer y segundo matrimonio, la crianza de hijos y nietos. Se insertan también referencias a las políticas estatales del gobierno de Pinochet y cómo estas se viven en el sector. El capítulo sexto relata un viajc a Pucrto Saavedra para buscar el agua que C.R. necesita... Reflexiona sobre el significado que da la machi al mundo de Prado Huichahue: "es el lugar fronterizo donde se intercambian todos los límites, donde las dos aguas se apozan intranquilas..."; "no la querían por bruja... -advierte-... por Kalku, porque dicen que... ¿No ves que habla con los espíritu? ¿Por qué crees que no ha querido que ninguna machi le enseñe?". Luego incluye la participación en el nguillatun; describe "[...] las ramadas humeantes albergaron los cuerpos en continuas rogativas, sus miembros incansables por las siete semillas de millalle, del chamico, que Carmela les dio de madrugada antes de ir a la cancha a encontramos con Kalfuchuan...".
Luego prosiguc "[...] sietc semillas como siete peldaños para ir al cielo despejado, para llegar al mundo del medio por la mañana cuando estén pidiendo por las cosechas...". Para finalmente relatar la parada por la peña de la gringa... en donde intercala estrofas de canciones... y su nuevo encuentro con los alemanes... con Wolfgäng.

El penúltimo capítulo lo dedica al relato que le ha hecho C: "Así ha ido caminando mi vida... Contra todos los que me envidian he salido adelante, porque cuando uno tiene el don, la gente lo envidia... Ya cuando me decidí a ser médico pasó as '́'... Aquí le revela su nombre: Menguante Aukinko y el significado del mismo. Aquí le enseña "claves de la cultura", le relata casos de otras machis, diferente a ella. Aclara pasajes de su vida: "Por eso siempre digo que hay que rogar a Dios Ngenechen... Esa es la riqueza del mapuche"...

Finalmente, el capítulo octavo relata un encuentro de pocos años atrás y que muestra cambios materiales en el estilo de vida de Prado Huichahue... donde la biografiada no ha aceptado poner tablas de pino ni cocina a gas... en este encuentro reitera pasajes de la vida de la machi.

La segunda parte se inicia con palabras que le habría dictado la machi: "Yo digo que las sicmbras son como los amores...". Incluye una canción de amor con el trompe, una historia de Choigüe y Pilmiquen, la historia de Wollin, el zorro y cl viejo Willin; concluye con el significado de los sueños, costumbres de pájaros, lo que tienen escrito las plantas y el nguillatun de Trampulo.

Todos estos son relatos que C.R. le habría contado a la autora... "Vamos a conversar del nguillatun de Trampulo, me dijo Carmela un día...".

\section{¿Crisis de la antropología? ¿Construyendo épocas o estableciendo lealtades protectoras?}

Los antecedentes expuestos muestran una triada compleja de relaciones de doble flujo: desce la sociedad nacional hacia la sociedad mapuche, primeramente a través de las políticas indigenistas que desde el siglo pasado se han implementado en relación al territorio y a continuación y en forma simultánea hacia los propósitos y formas de intervención de ésta en aquélia, a través de las distintas organizaciones que han emergido y coexistido durante el presente siglo.

En efecto, se constata que la sociedad mapuche se ha expresado en el plano de las decisiones sociales y privadas a raíz del impacto que la inclusión forzada en una cultura diferente ha tenido en la vida individual, familiar y comunitaria, a través de las organizaciones que intentan, en un esfuerzo notable, comprender o intentar controlar un sistema implacable de relaciones interétnicas, desigual y discriminatorio. 
En estas relaciones han jugado un papel importante dos tipos de conocimientos: a) el social, cotidiano o de sentido común, basado en imágenes globales dependientes de modo directo de los intereses de quienes las construyen y de sus posibilidades de conocer $\mathrm{y}, \mathrm{b}$ ) cl conocimiento especializado, que ha debido recorrer un largo camino hasta entender que juega un papel en las relaciones intcrétnicas vigentes (Durán, 1999).

En efecto, este segundo tipo de conocimicnto ha afectado la sensibilidad del pueblo mapuche y de su gente cuando se ha obtenido sin su participación y aún a espaldas de éste. En términos de conocimicnto transcultural, no obstante, ha despertado la preocupación de importantes sectores nacionales que han llegado a confrontar con éstc las políticas estatales, basadas mayormente en conocimientos intercsados y estcreotipados. Este conocimiento transcuitural, particularmente aquel quc asumc la propia relación interétnica como su objeto, es producto de la reflexión profunda que scctores especializados centrales -mayormente europeos y algunos norteamericanos- han hecho de la concepción misma de realidad social y del conocimiento de orientación científica. Este tipo de conocimiento ha sido utilizado de modo explícito por algunos sectores de la dirigencia mapuche para sus propios propósitos. Ha sido, por otra parte, rechazado por sectores oficialistas y/o del mundo indigenista.

Entonces, se trata de un tipo de rclaciones que, por un lado, es contestatario a un estado de situación y, por otro, promuevc abiertamente la mantención o el cambio profundo de tal estado. Las reacciones y contrarreacciones no son necesariamente simultáneas, directas ni explícitas. Tampoco las posibilidades de establecer nexos con sentido son imposibles, pero el impacto de estas vinculaciones en el tema de fondo de las relaciones interétnicas y que concicrne a la distribución del poder social, económico y cultural que se le asigne al pucblo originario en la socicdad nacional y al papel real y simbólico que este puede jugar en ella, es variado. Esta variabilidad, de nuevo, concierne a la posición de poder de la concepción hegemónica. Así, esta variabilidad de concepciones y consecuentes acciones constituye una riqueza de los últimos tiempos, sobre todo si se considera su condición de optativa; pero también puede evaluarse como profundamente frustrante si se la estima como una situación o un sistema de opciones condicionadas.

En relación a la última obra comentada, diversas voces se levantaron para opinar. Algunos antropólogos dijcron: "Es fácil de leer... es pura litcratura...". "Puede ser interesantc porque nos permitirá hablar de la salud intercultural...". "De primera lo empecé a lecr con interés, pero luego, con las salidas de literatura, lo dejé...". Algunos mapuches cspecialistas: "¿Para qué sirve este libro?; no es biografía porque en el centro está la antropóloga, no la machi... Es un pésimo favor a la antropología...". Gente mapuche no especialista: "No sé de qué puede servir hablar de trivialidades... Esto no es antropología... ni biografía... Es sólo entretenido...". Gente no mapuche no especialista: "Me encantaría leer el libro... me tinca que cuenta cosas increíbles...".
No es este el contexto con el que nos gustaria concluir esta revisión. Sin embargo, no es posible desconocer que está relacionado con el que sí nos interesa: el de la relaciones interétnicas que se establecen, se niegan o sc re - crean a través del tiempo en torno a/o con los mapuche, dependiendo de la posición adoptada por el especialista. En este tipo particular de relaciones el otro las establece basándose en el sentimiento de pertenencia a un grupo o etnia, desde el cual tienen sentido actitudes y prácticas relativas a imágenes de mapuche $y$ de los chilenos y/o de los no mapuche. Estas imágenes fluyen desde etapas tempranas del siglo XX, a través de las prácticas respectivas, en forma coherente e incluso incoherente con ellas. En efecto, aunque cada tipo de relación pareciera tener un origen único y un destino pre-diseñado, se constata que los individuos y sectores buscan expresiones diversas a lo largo de la vida, dependiendo de cómo csa pertenencia de origen se vive y/o se la determina por parte de estructuras sociales.

En estc contexto interrelacionado distinguimos, a lo menos, las siguientes imágenes:

1. Visión del mapuche incorporado a la sociedad chilena y sujeto a sus leyes y a sus mandatos sociales.

2. Visión del mapuche como una entidad racial y social única, somctido a las leyes del Estado chileno.

3. Visión del mapuche como un sector que requiere civilizarse para no constituirse en una carga para la sociedad y el Estado.

4.Visión del mapuche como un pueblo atávico que no cambiará su condición de tal.

5. Autoimagen del pueblo mapuche como indómito, valiente, derrotado, incomprendido, atropellado, que puede participar en la sociedad nacional si el Estado le otorga oportunidades de educarse y civilizarse.

6. Autoimagen del pueblo mapuche como una nación noble, con su propia cultura y estilo de vida que debe ser aceptado como tal y al que se ic deben otorgar las mismas facilidadcs que al no mapuche para reproducirsc.

7. Autoimagen del pueblo mapuche como un sector social pobre, que debe asociarse al pobre no mapuche y constituirse en fuerza social que abogue por justicia, igualdad de derecho, respeto, etc., dentro de la sociedad nacional.

8. Grupo social, minoría étnica, pueblo indígena similar a otros de América, con una cultura en extinción o cn revitalización.

9. Sociedad y/o cultura inserta de modo forzado en una sociedad nacional que no reconoce su participación en la Constitución e historia de la nacionalidad y cuyo futuro depende del tipo de interrelación que predomine entre ambas sociedades.

Se interrelacionan aquí de un modo total o parcial visiones, autoimágenes mapuche de un cierto nivel autonómico, algunas de las cuales plantean desafíos a los no mapuche respecto de cuestiones tales como: 
- El territorio, su eliminación, mantención o recuperación. - La participación de los miembros de estos pueblos en los proyectos nacionales, sea a través de propuestas estatales o privadas, o de propuestas que emerjan de los sectores étnicos.

¿Con qué tendencia ideacional y accional asociar Sueño con Menguante, la última obra considerada? ¿A la visión del pueblo atávico que sc rige por sus propias leyes, desconociendo las de la civilización? ¿A la del pucblo misterioso, lleno de supersticiones, de secretos inconfesados? ¿De qué modo contribuirá al sistema de relaciones interétnicas?

Por otro lado:

- ¿A qué tipo de antropología podría también responder? ¿A la del desenfreno individualista y egocéntrico, pero que, igual que la tendencia opuesta, intenta construir conocimicnto?

- ¿A la antropología que busca y restablece la relación sujeto - objcto sobre otros principios, por ejemplo, los del amor? ¿ Qué posibilidades tiene esa antropología? - iA la antropología que, situada desde el contexto en el cual permanece la reserva patrimonial más significativa de este pueblo, intenta re-fundar relaciones interétnicas más equilibradas?

Los argumentos están expuestos, las preguntas continúan... A modo ilustrativo, puede inferirse que, por ejemplo, el sector mapuche intclectual, interesado en el conocimiento cultural e inciuso en el transcultural, no encontrará en la última obra elementos que contribuyan a este proceso. ¿Valorarán la autocondición de "escogida" de la autora?, o ¿dirán que se trata de "otra huinca que intenta penetrar en los secretos mapuche sin lograrlo"?

Desde la perspectiva antropológica que intenta situarse en la corriente del pluralismo epistémico, la obra es un guión híbrido que no culmina, ni en labor etnográfica ni en antropológica propiamente tal. Muestra el quehacer antropológico como algo extraordinariamente casual con tendencia a literaturizar el objetosujcto, abriendo una duda razonable respecto a si el propósito final es disciplinario o el propio de una obra de "best seller".

\section{Recapitulación}

En esta revisión hemos considerado un itinerario de seguimiento de obras antropológicas contemporáneas relativas a la población indígena, particularmente mapuche, desde los ' 60 , deteniéndonos un poco más en aquellas coetáneas. El propósito ha sido develar paradigmas no sólo teónicos, sino también sociaies $y$ dc proyección pedagógica, considerando la posición en la que nos encontramos, de cara al sujeto que nos interesa desde la disciplina. El recorrido analítico tiene sentido respecto de, por un lado, la variedad de enfoques $y / 0$ paradigmas -tal como estos se conciben en la academia- $y$, por otro, los eventuales im- pactos que estos tienen en los distintos públicos que acceđen a cllos, una cuestión que recićn en la última década del sigio que concluye está formando parte de la preocupación antropológica nacional y regional.

El breve recorrido presentado nos ha permitido ver cuestiones epistemológicas y socioculturales. En primer lugar, ha cobrado relieve el hecho de que en un paradigma del quehacer discipiinario pueden coincidir como base fundante el o los acercamientos teóricos, la posición situacional del especialista respecto del sujeto de su observación e interpretación y una visión o perspectiva reflexiva que incluye estos factores en las relaciones directas con ese sujeto y en el marco de relaciones sociales más amplias y estructuradas que, en la segunda mitad del siglo, postulamos que debieran ser las llamadas relaciones interétnicas. Hemos advertido que, desde La Araucanía, emerge hoy un tipo de antropología académica sobre la temática de los pueblos indígenas, precisamente porque se está perfilando de mejor modo este último componente del paradigma y la posibilidad cierta de diferenciar incluso los paradigmas coetáneos. Así, aunque con esta perspectiva analítica cada especialista puede producir obras de diferente impacto y en el marco de la evolución de la disciplina, ello no constituiría materia de controversia, otra situación emerge si el estilo de relaciones con estos pueblos es, o muy difuso y confuso, a ser cada vez más claramente definido en concordancia con el uso reflexivo de los distintos componentes paradigmáticos. Esta última condición vigilante hoy día nos parece insoslayable, tomando en cuenta que los propios sujetos, en estc caso mapuche contemporáneos, están usando las distintas antropologías para sus respectivos fines sociales y/o políticos. A ello hay que agregar que, en contextos interétnicos como el nuestro, el componente académico y formativo constituye parte de la escena social y se nutre consciente o inconscientemente de ella. El desafío pendiente es ver cómo estos distintos componentes conformarán algún día un nuevo paradigma antropológico, pertinente a la necesidad de un cambio sociocultural profundo.

\section{Bibliografía}

ALONQUEO, M. (1979), Instituciones religiosas de! pueblo mapuche, Nueva Universidad U. C.

BACIC, R., DURAN, T. y PEREZ, P. (1996), Muerte y desaparición forzada en La Arauania: Una aproximación étnica, LOM, Santiago, Chile. CATRIQUIA, D. y DURAN, T. (1996), "Del involucramiento a la reflexión. Politicas educacionales hacia la sociedad mapuche", en Pueblos Indigenas y Educación $N^{D} 37-38$, Abya Yala/GTZ, Quito, Ecuador.

CATRIQUIA, D. y DURAN, T. (1996), "El nombre personal entre los mapuche", en Acatas de Lengua y Literatura Mapuche, UFRO, Ternuco, Chile.

CITARELLIA, L. et. al. (1995), Medicinas y culturas en La Araucanía, Sudamericana, Santiago, Chile.

CLIFFORD, J.y MARCUS, E. (1991), Fetóricas de la antropologia, Jucar Universidad, España.

DURAN, T., QUIDEL, J. y HAUENSTEIN, E. (1997), Conocimientos y vivencias de dos farnilias wenteche sobre medicina mapuche. Mapuche lawentüwūn epu reyñma wenteche ñi kimûn mew, LOM, Santiago, Chile. DURAN, T., QUIDEL, J. y CATRIQUIR, D. (1994), "Health among the mapuche of Chile", en Gender, heaith and sustainable development: A 
Latin American perspective. Procedings of a workshop held in Montevideo, Uruguay, !RDC, Canadá.

DURAN, T. (1995), "Revisión critica de dos tesis para el desarrollo", en Documento Pueblos Indigenas y Desarrollo, UFRO, Temuco, Chile.

DURAN, T. (1996), "¿Qué se entiende por interculturalidad? Una respuesta desde la antropologia sociocultural", en Actas de! Primer Seminario Latinoamericano de Educación Intercultural Billingūe.

DURAN, T. y CATRIQUIR, D. (1996), "Ad eu kimün. Principios educativos mapuche. Base para un curriculum en educación. interculturai bilingũe", en Actas del Primer Seminario Latinoamericano de Ëducación Intercultural Bitingūe.

DURAN, T., CATRIQUIR, D. Y LLANQUINAO, G. (1997), "Líneas de conocimiento en tomo a la educación bilingūe mapuzungun-castellano", en Pueblos Indigenas y Educación N*37-38, Abya Yala/GTZ, Quito, Ecuador. DURAN, T. (1999), "El papel del conocimiento en las relaciones interétnicas y el ciesarrollo, Documento inédito presentado en el Seminario Pueblo Mapuche, Desarrollo y Autogestión, UFRO, Temuco, Chile. FAAON, L. (1961). Mapuche social structure, Institutional reintegration in a patrilineal society, Instituto Indigenista Americano, México.

FARON, L. (1964), Antūpaiñamko: Mapuche morality and its ritual atributs, University of Pittsburgh Press, U.S.A..

FOERSTER, R. y MONTECINO, S. (1993), Organizaciones, lideres y contiendas mapuches (1900-1970), CEM, Santiago, Chile.
FOERSTER, R. y VERGARA, I. (1996), "¿Relaciones interétnicas o relaciones fronterizas?", en Excerpta $N^{\circ} 5$, Julio, Santiago, Chile.

GARCIA-CANCLINt, N. (1992), Culturas hibridas. Estrategias para entrar y salir de la modernidad, Sudamericana, Buenos Aires, Argentina. GEERTZ, C. (1989), El antropólogo como autor, Paidós, Barcelona, España.

GELLNER, E. (1994), Posmodernismo, razón y religión, Paidós, Barcelona, España.

HILGER, ?. (1957), Araucanian child life and its cultural background, Smithsonian Institute, U.S.A.

HIL.GER, I. (1966), Huenūn Namku: Un indio araucano de Los Andes, University of Oklahoma Press, U.S.A.

MANQUILEF, M. (1974), "Comentarios del pueblo araucano", en Anales de la Universidad de Chile, Tomo y lt, Santiago, Chile.

MONTECINO, S. (1999), Sueño con Menguante, Sudamericana, Chite. STUCHLIK, M. (1976), Life on a half share. Mechanism of socia! recruitment among the mapuche of southern Chile, Billing \& Sons, Gran Bretaña.

VIDAL, A. (1999), "Políticas legislativas en Chile, El caso de las tierras y territorios mapuches", en CUHSO, Volumen Especial N 1, Legislación indigena, tierras y pueblo mapuche, Centro de Estudios Socioculturales, Universidad Católica de Temuco, Chile. 